\title{
Online Particle Counter for Continuous Fluid Condition Monitoring
}

Damas has developed a new particle counter (Pamas OLS50P) to meet the increasing demand for online fluid condition monitoring. This new stationary instrument has been successfully implemented in several customer plants. All types of light extinction sensors of the Pamas HCB-LD series can be integrated in the new unit. If required, the sensor can be built of resistant material so that it can be used for the analysis of all types of liquids and critical fluids, from water to strong acid. The particle counter has eight different size channels and can therefore measure the following particle sizes: $>4 \mu \mathrm{m}(\mathrm{c}),>6$ $\mu \mathrm{m}(\mathrm{c}),>10 \mu \mathrm{m}(\mathrm{c}),>14 \mu \mathrm{m}(\mathrm{c}),>21$ $\mu \mathrm{m}(\mathrm{c}),>25 \mu \mathrm{m}(\mathrm{c}),>38 \mu \mathrm{m}(\mathrm{c})$ and $>70 \mu \mathrm{m}(\mathrm{c})$. For data transfer, the user has the choice between digital and analogue interfaces. Two different reporting and evaluation tools are available for analysing the measuring results: the visualisation software POV can be used for longterm trend monitoring. The component test software PCT provides online monitoring of components in industrial plants and component test rigs. With the aid of the software tools, measuring results can be reported according to common cleanliness standards. Furthermore, the measuring parameter can be set up individually and adapted to the specific application profile.

www.pamas.de

\section{New line of automatic spray guns with quick-change adapter plates}

W alther Pilot presents a new automatic spray unit in a compact design. It can be used for every assignment in wet painting and when applying adhesives. The newly developed Pilot WA 900 involves a simple modular system that makes possible every combination that might be required for coating. There are two basic models - one with internal control, the second prepared for external adjustment of the spray parameters. Two different quickchange adapter plates have been de- veloped and each can be used with either model. The user can choose between a standard adapter plate (nickel-plated aluminum) and a lowprofile adapter plate made of stainless steel. The units can be connected to a branch line or to a material circulation ring line. In the Pilot WA 900 - as with most Walther Pilot automatic spray guns - the forward section and all the parts in contact with the material are made of stainless steel (the only exception being the standard plate). The PTFE finish on the body of the spray gun makes this unit especially easy to clean. In regard to the atomizing technique, too, the user has several options to choose from. In addition to conventional and HVLP spray technologies, this manufacturer also offers the newly developed HVLP-Plus nozzle technology. This will help to save material and compressed air on the one hand while still guaranteeing the finest atomization at high working speeds.

Phone: +49 202 787-0, www.walther-pilot.de

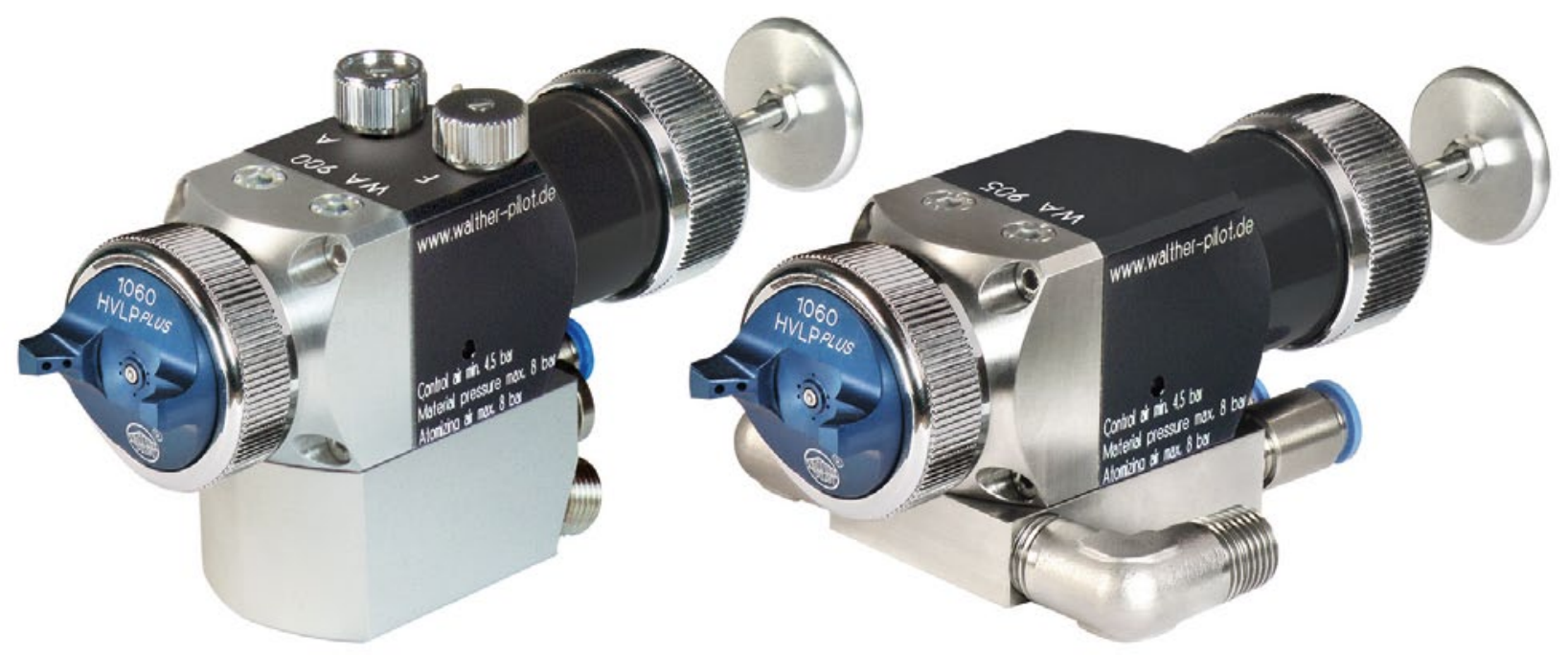

